Ekuitas: Jurnal Pendidikan Ekonomi

Volume 9, Number 1, Tahun 2021, pp. 172-178

P-ISSN : 2354-6107 E-ISSN : 2549-2292

DOI : $10.23887 /$ ekuitas.v9i1.30638

Open Access: https://ejournal.undiksha.ac.id/index.php/EKU

\title{
Peran Kesadaran Halal dan Efektivitas Iklan Youtube Terhadap Minat Pembelian Kosmetik Sariayu
}

\author{
Elvira Dewi Santika1* ${ }^{*}$, Asep Muhamad Ramdan², R Deni Muhammad Danial ${ }^{3}$ \\ 1,2,3 Universitas Muhammadiyah Sukabumi, Sukabumi - Indonesia
}

\section{A R T I C L E IN F O}

Article history:

Received December, 25 2020

Received in revised form June, 72021

Accepted June, 82021

Available online June, 28 2021

\section{Kata Kunci:}

Efektivitas iklan, kesadaran halal, kosmetik, minat beli.

Keywords:

Advertising effectiveness, buying interest, cosmetics, halal awareness.

\begin{abstract}
A B S T R A K
Penelitian ini bertujuan untuk mengetahui adanya pengaruh kesadaran halal dan efektivitas iklan terhadap minat pembelian kosmetik sariayu. Teknik analisis data yang digunakan yaitu analisis regresi linear berganda dan menggunakan teknik sampel non-probability sampling. Pengumpulan data dilakukan dengan penyebaran kuesioner menggunakan google form kepada 103 responden di kota Sukabumi. Pengolahan data menggunakan software IBM SPSS versi 24. Hasil penelitian menunjukan bahwa secara simultan dan parsial kesadaran halal dan efektivitas iklan terhadap minat beli berpengaruh secara signifikan dan positif terhadap minat beli. Hasil dari uji $\mathrm{F}$ yaitu dari nilai $F_{\text {hitung }}$ 75,727 > 3,08 menunjukkan bahwa $F_{\text {hitung }}$ lebih besar dibandingkan $\mathrm{F}_{\text {tabel }}$ dan hasil korelasi pada penelitian ini memiliki nilai yang sangat kuat yaitu sebesar 0,776 sehingga dapat disimpulkan bahwa dari masing masing variabel adanya pengaruh antara variabel kesadaran halal dan efektivitas iklan terhadap minat beli. Hasil pada uji t yaitu $6.908>1.983$ menunjukan bahwa $T_{\text {hitung }}$ lebih besar daripada $\mathrm{T}_{\text {tabel }}$ sehingga dapat disimpulkan bahwa pada variabel kesadaran halal dan efektivitas iklan memiliki pengaruh yang signifikan terhadap minat beli.
\end{abstract}

\section{A B S T R A C T}

This study aims to determine the effect of halal awareness and advertising effectiveness on purchase intention. The data analysis technique used is multiple linear regression analysis and non-prbability sampling techniques. Data collection was done by distributing questionnaires using google form to 103 respondents in Sukabumi and data process using IBM SPSS software version 24. The simultaneously and partially halal awareness and advertising effectiveness on purchase intentions had a significant and positive effect on purchase intentions. The results of the $F$ test, namely the value of $F_{\text {count }} 75,727>3,08$ shows that $\mathrm{F}_{\text {count }}$ is greater than $\mathrm{Ftable}_{\mathrm{a}}$ and the results of the correlation in this study have a very strong value, namely 0,776 it can show that from each variable there is an influence between the halal awareness variable and the effectiveness of advertising on buying interest. The results of the t-test, which is $6.908>1.983$, show that Tcount is greater than Ttable, so it can be concluded that the halal awareness and advertising effectiveness variables have a significant influence on buying interest.

\footnotetext{
* Corresponding author.

E-mail : elviradewis9@ummi.ac.id (Elvira Dewi Santika)
} 


\section{Pendahuluan}

Semakin banyaknya pertumbuhan penduduk di Indonesia, sangat menjanjikan Indonesia menjadi pasar bagi perusahaan kosmetik. Secara keseluruhan perindustrian kosmetik menargetkan terutama konsumen kaum wanita, dan berkembang menginovasikan dengan produk bagi kaum pria juga (Kementrian Perindustrian Republik Indonesia, 2013). Setiap tahun penjualan kosmetik menurut data Persatuan Perusahaan Kosmetik Indonesia seiring berjalannya waktu terus meningkat, peningkatan ini di pacu oleh naiknya volume penjualan dan turunnya tarif masuk dengan adanya perjanjian dagang yang bebas (Putri, 2018).

Bisnis kosmetik di Indonesia akan semakin maju apabila didukung oleh salah satu kelebihan atau karakteristik pada produk tersebut yang di tuju oleh sesuatu yang lebih cantik dan sehat. Hal ini dapat mengakibatkan dampak yang sangat baik dan kesempatan bagi Industri Kosmetik di Indonesia di masa yang akan datang (Purba, 2019). Salah satu dorongan yang membuat konsumen ingin menggunakan suatu kosmetik salah satu nya dengan adanya kosmetik yang sehat dan aman digunakan bagi konsumen yaitu kosmetik yang sudah halal salah satu hal tersebut bisa membuat kunsumen percaya dan tidak akan berfikir panjang untuk menggunakannya.

Hadirnya kosmetik halal di perindustrian kosmetik di Indonesia itu terjadi karena Indonesia merupakan negara dengan mayoritas Islam tertinggi dan akan terus meningkat setiap tahunnya, perkembangan yang menganut agama islam mencapai dengan persentase sebesar $87,17 \%$ dan pada tahun 2020 penduduk Islam di Indonesia mencapai 256,82 juta jiwa (Kusnandar, 2019).

Semakin industri kosmetik menganggap bahwa kesadaran halal dari produk itu bisa membuat percaya seorang konsumen maka perusahaan dalam menciptakan produknya harus biasa lebih dahulu mrmperhatikan ada atau tidak nya halal dalam produk kosmetik tersebut. Namun, seorang perempuan di segala usia tidak terlalu mementingkan produk yang halal tetapi kecocokan pada kulit yang akan menjadi pertimbangan konsumen dalam membeli produk (Rahmah et al., 2020). Sehingga konsumen akan berminat untuk segera membeli produk itu dan perusahaan menginginkan produknya dipakai dengan jangka waktu lama oleh konsumen. Maka perusahaan harus mampu mempromosikan produknya sehingga bisa lebih mudah dikenali oleh konsumen dengan cara promosi melalui efektivitas iklan, salah satunya di jejaring sosial youtube. Karena efektivitas iklan ini bisa mempengaruhi konsumen agar konsumen tahu pesan apa yang disampaikan oleh perusahaan. Konsumen pun akan muncul minat pembelian pada produk yang di iklan kan dan tentunya iklan yang disampaikan dapat dirasakan oleh konsumen yang telah menggunakan produk tersebut.

Sariayu adalah salah satu kosmetik yang hadir meramaikan adanya kosmetik halal di Indonesia. Sariayu didirikan oleh PT. Martino Berto pada tahun 1981. Kosmetik sariayu sudah memiliki sertifikat halal pada tahun 2012 hingga saat ini karena bahan yang digunakan tidak ditemukannya bahan yang membahayakan karena saat ini perilaku konsumen cara melihat produk tersebut sudah berbeda. Sariayu memiliki dan menjual berbagai macam kosmetik dan kosmetik yang dijual konsumen di Kota Sukabumi ada yang sudah mengetahui dan ada juga belum mengetahui bahwa kosmetik memiliki banyak macam kosmetik yang dijual. Berdasarkan hasil riset yang telah dilakukan oleh Top Brand Index dilihat pada tabel 1.

Tabel 1. Data Penjualan Produk Kosmetik Sariayu

\begin{tabular}{ccccc}
\hline No. & Jenis Kosmetik & $\mathbf{2 0 1 8}$ & $\mathbf{2 0 1 9}$ & $\mathbf{2 0 2 0}$ \\
\hline 1 & Masker Wajah & $19,1 \%$ & $12,7 \%$ & $15,0 \%$ \\
2 & Blash On & $8,7 \%$ & - & - \\
3 & Pelembab Wajah & $10,6 \%$ & - & - \\
4 & Lipstik & $7,2 \%$ & - & - \\
5 & Bedak Muka Tabur & $10,4 \%$ & $4,5 \%$ & $4,6 \%$ \\
6 & Eyeliner & $8,4 \%$ & - & - \\
7 & Foundation & $7,2 \%$ & - & - \\
8 & Lip Gloss & $7,0 \%$ & $6,1 \%$ & $4,5 \%$ \\
9 & Bedak Muka Padat & $9,3 \%$ & - & - \\
\hline
\end{tabular}

Sumber: (Top Brand Index, 2020)

Dari data di atas pada top Brand Index pada produk Sariayu dari tahun ke tahun mengalami naik turun dari tahun 2018 sampai 2020, dan dalam data tersebut sangat jelas bahwa kosmetik yang dijual pada tahun 2018 tidak di jual di tahun 2019 dan 2020, penjualan pada tahun 2019 ke 2020 pun tetap mengalami 
naik turunnya penjualan. Hal ini disebabkan karena peminatnya berkurang dari tahun ke tahun. Oleh karena itu produk Sariayu harus ditingkatkan lagi penjualannya, salah satunya kesadaran halal yang harus dikenalkan membuat konsumen percaya dan fakta yang bahwa konsumen dalam melihat dan memilih produk khususnya kecantikan bukan dilihat dari produk yang disukai nya tetapi mengacu pada ada atau tidaknya kehalalan pada produk kecantikan itu (Nathasi, 2017). Dan melakukan promosi dengan efektivitas iklan yang dilakukan melalui jejaring sosial youtube.

Tentu adanya kesadaran halal yang diciptakan oleh perusahaan untuk membuat konsumen tahu dan percaya pada produk sariayu, karena apabila ada dorongan positif bahwa kosmetik itu bagus dan apalagi halal maka konsumen lain pun akan segera melakukan pembelian, fenomena ini ditemukan (Mustikasari, 2019). Dan efektivitas iklan yang dilakukan dengan promosi melalui youtube maka akan timbulnya minat beli konsumen dan dapat menarik konsumen sehingga timbulnya kembali kenaikan penjualan, karena pada minat beli dalam sifat konsumen apabila konsumen merasa produk itu cocok maka konsumen tersebut akan mereferensikan produk tersebut kepada konsumen lain apabila merasa produk yang dipakai cocok. Pengalaman pelanggan yang positif dapat memperoleh juga membantu pelanggan lain untuk membedakan pengalaman, jika suatu produk tidak dikelola dengan baik pengalaman pelanggan tersebut akan menimbulkan persepsi yang negatif (Ramdan et al., 2021)

Dengan adanya latar belakang dalam penelitian ini maka pada kesadaran halal, efektivitas iklan, dan minat beli bertujuan untuk mengetahui bagaimana kesadaran halal, efektivitas iklan, dapat mempengaruhi minat beli. Sehingga tujuan penelitian ini untuk mengukur peran kesadaran halal dan efektivitas iklan terhadap minat beli konsumen.

Minat dalam membeli yaitu salah satu keinginan seseorang atau konsumen untuk segera membeli dalam tindakan yang merupakan bagian dari proses menuju kearah pembelian yang dilakukan atau segera dilaksanakan oleh konsumen (Dimyati et al., 2018). Pada minat pembelian ini dipengaruhi pada suatu rangsangan dari suatu tempat atau keadaan diluar dari produk (Eliza et al., 2018). Minat beli adalah salah satu pembuktian mental konsumen yang meununtun rencana dalam pembelian beberapa produk dengan suatu merek, hal ini sangat dibutuhkan oleh pemasar untuk bisa menegtahui minat dalam membeli pada suatu produk dan hal ini adalah salah satu pemasar untuk mengetahui perilaku konsumen dalam memasarkan di masa yang akan datang (Yuliyzar \& Enjelita, 2020). Perilaku konsumen adalah setiap tindakan disetiap apapun yang telah ddapatkan, dikonsumsi, dan dihabiskan dalam bentuk produk atau jasa, dan termasuk dalam segala keputusan yang menciptakan atau mendorong tindakan ini, dalam memahami konsumen dan pengembangan strategi pemasaran yang benar kita harus memahami apa yang konsumen pikirkan (kognisi), rasakan (pengaruh), lakukan (perilaku), dan kejadian sekitar, yang berpengaruh dan dipengaruhi oleh apa yang konsumen pikirkan, rasakan, dan dilakukan konsumen (Nugroho. J. Setiadi, 2019)

Banyak sekali dimensi yang bisa mengukur minat belisalah satu nya menurut (Septiani, 2018) ada empat dimensi untuk mengukur minat beli yaitu minat transaksional, minat referensial, minat preferensial, dan minat eksploratif. Dimensi ini juga digunakan oleh (Benowati \& Purba, 2020).

Minat beli adalah keadaan dimana seseorang ingin mencoba dan atau mempunyai suatu produk, minat beli hadir setelah konsumen memiliki rangsangan dari sebuah produk yang dituju sebelumnya, dari yang konsumen lihat tersebut akan munculnya ketertarikan untuk mencoba sebuah produk yang dilihatnya dan akhirnya muncul suatu keinginan untuk membeli agar memiliki produk tersebut (Suryowati \& Nurhasanah, 2020).

Kesadaran halal adalah sesuatu yang konsumen ketahui yaitu pengetahuan muslim tentang adanya sebuah konsep halal, tata cara halal, dan menganggap bahwa apapun yang dikunsumsi harus halal dan halal adalah hal yang sangat penting bagi umat muslim(Izzudin, 2018). Kesadaran merupakan keadaan seseorang mampu dalam memahami, merasakan, dan selalu sadar pada peristiwa atau benda, kesadaran yaitu suatu bentuk mengenai penyiratan sebuah pemahaman dan suatu persepsi terhadap adanya peristiwa ataupun objek (Imah, 2020).

Menurut Yunus, et al., (2014) ada beberapa dimensi untuk mengukur kesadaran halal, yaitu sebagai berikut. (1) pemahaman pengetahuan produk, yaitu perkumpulan informasi mengenai produk. (2) sadar akan adanya pencantuman, artinya setiap produk apapun itu harus diperhatikan dalam pencantuman halalnya. (3) kebersihan dan keamanan dalam sebuah produk, yaitu kondisi yang dijauhkan dari adanya pencemaran kimia, dan hal apapun yang dapat mengganggu.

Setiap konsumen yang akan membeli pasti dipengaruhi oleh beberapa hal diantara nya sikap konsumen yang melihat produk dari suatu merek tertentu (Rangkuti, 2013), jadi apabila merek pada produk yang akan dibeli halal maka konsumen akan percaya dan langsung membeliPada (Widyaningrum, 2019) menyatakan adanya hubungan yang positif dan signifikan antar kesadaran halal dan minat beli, arti yang dimaksud yaitu apabila konsumen merasa kesadaran halal itu penting maka minat beli pada produk akan sangat tinggi karena semakin tinggi kesadaran halal akan semakin tinggi pula minat belinya. 
H1: Kesadaran halal berpengaruh positif dan signifikan terhadap minat beli.

Pada saat ini iklan masih sangat penting digunakan di dalam memasarkan produknya walaupun produk itu sudah banyak dikenal, iklan adalah salah satu cara untuk membuat konsumen mengetahui produk yang akan dijual tersebut seeperti apa sehingga akan timbul rasa ingin mempunyai produk tersebut karena iklan mampu membuat konsumen mengetahui keunggulan yang ada pada produk tersebut, pengiklanan ini tidak hanya dilakukan kepada produk baru saja melainkan produk yang sudah ada sejak lama, hal ini adalah cara agar produk lama masih bisa eksis dan tidak akan digantikan oleh produk baru (Permana, 2015). Hal ini berarti efektivitas iklan sangat dibutuhkan dalam memasarkan produknya dari produk yang lama sampai produk baru.

Menurut Durianto dalam jurnal (Narita \& Suyanto, 2019) EPIC model merupakan salah satu pengukuran efektivitas iklan untuk mengukur adanya dampak komunikasi dari iklan dan mempunyai empat dimensi yaitu (1) Empathy, adalah keadaan dimana dirinya merasa sama dengan orang lain atau kelompok lain, (2) Persuasion, adalah perubahan seseorang yang disebabkan oleh komunikasi promosi, (3) Impact, adalah apakah sebuah iklan mampu melebihi pesaing dan apakah mampu menangkap perhatian kepada konsumen, (4) Communication, adalah konsumen mampu mengingat dan memahami pesan yang diberikan oleh iklan tersebut.

Iklan yang sangat efektif dan disenangi oleh penonton akan membuat konsumen merasa mendapatkan timbal balik karena terpengaruhi oleh iklan yang disampaikan dan akan timbul rasa untuk membeli dan minat beli akan timbul pada konsumen, oleh karena itu semakin banyak orang menggemari iklan tersebut maka akan timbul dan mempengaruhi rasa untuk membeli, merupakan tujuan terakhir dari efektivitas iklan (Anatariona, 2014). Hal ini didukung oleh hasil dalam penelitian yang menyatakan bahwa efektivitas iklan memiliki hubungan dan pengaruh yang positif dan signifikan terhadap minat beli menurut (Supriyatin, 2015).

H2: Efektivitas iklan berpengaruh positif dan signifikan terhadap minat beli.

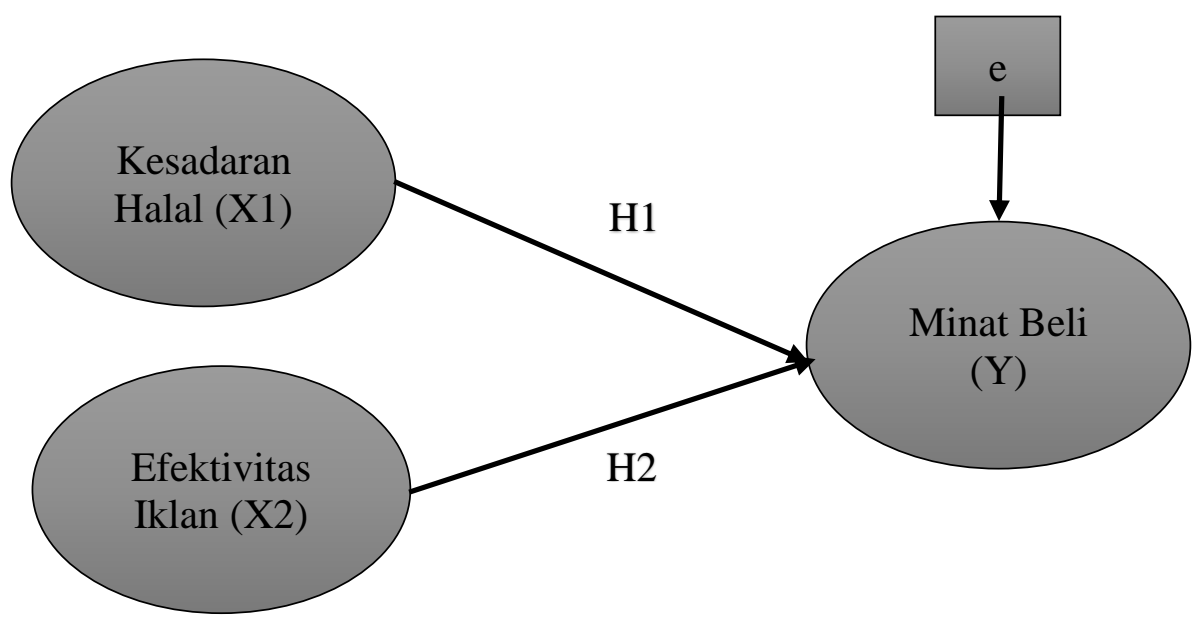

Gambar 1. Kerangka berpikir

\section{Metode}

Metode penelitian ini adalah kuantitatif dengan menggunakan metode deskriptif dan asosiatif. Objek dalam penelitian ini adalah konsumen yang menggunakan kosmetik Sariayu di Kota Sukabumi. Populasi dalam penelitian ini adalah konsumen yang telah menggunakan kosmetik Sariayu. Metode yang digunakan yaitu mrnggunakan teknik non probability sanpling dengan metode pendekatan accidental sampling dimana siapa saja yang bertemu dengan peneliti dapat digunakan sebagai sampel. Jumlah sampel yang digunakan dalam penelitian ini sebanyak 103 responden dengan menyebarkan kuisioner kepada konsumen kosmetik sariayu dan diolah menggunakan software IBM SPSS versi 24 . Teknik analisis data pada penelitian ini adalah regresi linier berganda. 


\section{Hasil dan pembahasan}

Uji F atau uji kelayakan model adalah cara untuk mengetahui suatu model bisa digunakan dan yang digunakan itu layak atau tidak didalam penelitian. Berikut hasil olahan data ditujukan pada tabel 2.

Tabel 2. Hasil Uji F

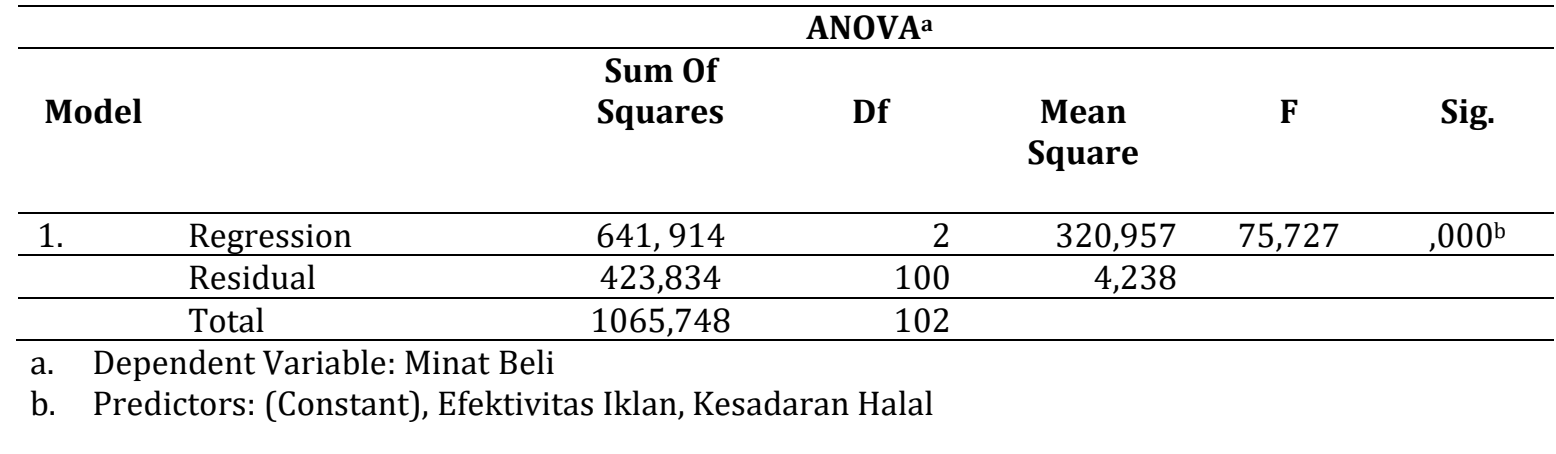

Sumber: Data diolah, 2020

Hasil dari uji $\mathrm{F}$ yaitu dari nilai $\mathrm{F}_{\text {hitung }} 75,727>3,08$ menunjukkan bahwa $\mathrm{F}_{\text {hitung }}$ lebih besar dibandingkan $\mathrm{F}_{\text {tabel. }}$ Dan nilai dari regresi mempunyai tingkat yang signifikan yaitu 0,000 $<0,05$. Maka dapat disimpulkan bahwa dari masing masing variabel adanya pengaruh secara simultan antara variabel kesadaran halal dan efektivitas iklan terhadap minat beli secara simultan dapat diterima.

Tabel 3. Hasil Koefisien Determinasi

\begin{tabular}{lcccc}
\hline Model & \multicolumn{5}{c}{ Model Summary } \\
& $\mathbf{R}$ & R square & $\begin{array}{c}\text { Adjusted R } \\
\text { Square }\end{array}$ & $\begin{array}{c}\text { Std. Error of } \\
\text { the Estimate }\end{array}$ \\
\hline 1 &, $776^{\mathrm{a}}$ &, 602 &, 594 & 2,05872
\end{tabular}

a. Predictors: (Constant), Efektivitas Iklan, Kesadaran Halal

b. Dependent Variables: Minat Beli

Sumber: Data diolah, 2020

Hasil olahan data diatas menunjukan bahwa besar nilai korelasi (R) yaitu 0,776 dan didapatkan koefisien determinasi (R Square) sebesar 0,602 maksud dari data ini yaitu pengaruh variabel kesadaran halal dan efektivitas iklan terhadap minat beli pengaruhnya sebesar 60,2 \% dan sisanya sebesar 39,8 \% dipengaruhi oleh variabel lain yang tidak diteliti pada penelitian ini.

Setelah itu dilakukan uji analisis regresi linear berganda, tujuannya untuk mengetahui pengaruh dari variabel independen apakah mampu mempengaruhi variabel dependen (Kurniawan \& Yuniarto, 2016). Kemudian pada saat mengajukan hipotesis, dilakukan uji t tujuan pada uji t ini adalah untuk menentukan hipotesis pada variabel satu dengan yang lainnya apakah mempunyai pengaruh atau tingkat signifikan yang sama atau tidak, pengolahan data menggunakan alat bantu SPSS.

Tabel 4. Hasil Regresi Linear berganda \& Uji T

\begin{tabular}{|c|c|c|c|c|}
\hline \multicolumn{5}{|c|}{ Kesadaran Halal (X1) } \\
\hline & Coeff & SE & $\mathbf{T}$ & P-Value \\
\hline Constant & 6,908 & 1,495 & 4,619 &, 000 \\
\hline Kesadaran Halal (X1) & 479 & ,141 & 3,388 & ,001 \\
\hline \multicolumn{5}{|c|}{ Efektivitas Iklan (X2) } \\
\hline & Coeff & SE & $\mathbf{T}$ & P-Value \\
\hline Constant & 6,908 & 1,495 & 4,619 &, 000 \\
\hline Efektivitas Iklan (X2) & ,481 & ,098 & 4,910 &, 000 \\
\hline
\end{tabular}

Sumber: Data diolah, 2020 
Hasil olahan data menunjukan nilai constant (a) sebesar 6,908 dan pada nilai kesadaran halal sebesar 0,479 dan pada nilai efektivitas iklan sebesar 0,481. Pada hasil ini dapat disimpulkan bahwa adanya pengaruh positif sehingga persamaan regresi nya adalah:

$\mathrm{Y}=\beta_{1} \mathrm{X}_{1}+\beta_{2} \mathrm{X}_{2}$

Maka

$\mathrm{Y}=0,479 \mathrm{X}_{1}+0,481 \mathrm{X}_{2}$

Berdasarkan hasil diatas hasil hipotesis pertama menunjukan nilai signifikan sebesar 0,01<0,05 dan nilai $T_{\text {hitung }} 3,388>1,983$. Sehingga dapat disimpulkan yaitu adanya pengaruh yang signifikan dan berpengaruh positif antara kesadaran halal terhadap minat beli.

Adapun hasil hipotesis yang kedua dibuktikan dengan nilai signifikan yaitu 0,000<0,05 dan nilai dari $\mathrm{T}_{\text {hitung }} 4,910>1,983$. Sehingga dapat disimpulkan pula adanya pengaruh yang positif dan signifikan antara efektivitas iklan terhadap minat beli.

Hasil dari uji t pada variabel kesadaran halal dan efektivitas iklan terhadap minat beli memiliki pengaruh secara parsial dan memiliki pengaruh secara simultan pada hasil dari uji $\mathrm{F}$

\section{Simpulan dan saran}

Berdasarkan hasil penelitian yang telah dilakukan diatas, maka didapatkan beberapa kesimpulan bahwa dari variabel independent yang terdiri dari dua variabel yaitu kesadaran halal (X1), efektivitas iklan (X2) terhadap variabel dependent yaitu minat beli (Y) dan dilakukan dengan teknik analisis regresi linear berganda dan dari hasil uji hipotesis secara parsial dan simultan menyatakan adanya hubungan yang positif dan signifikan antara variabel kesadaran halal dan efektivitas iklan terhadap minat beli.

Beberapa saran yang ditunjukkan untuk merek Sariayu dalam mengembangkan merek yang dikeluarkan harus sesuai dengan latar belakang pada saat ini sehingga ditingkatkan apa yang kurang dalam merek tersebut dan terciptanya minat beli yang dipengaruhi oleh kesadaran halal dan efektivitas iklan, sehingga penting bagi Sariayu dalam memperhatikan apa yang disadari oleh konsumen pada saat ini dan efek iklan dalam suatu produk, Sariayu juga perlu konsisten dalam menjual produk nya dari tahun ke tahun agar permasalahan yang terjadi saat ini dapat teratasi dengan baik.

\section{Daftar Rujukan}

Anatariona, R. (2014). Analisis pengaruh efektivitas iklan televisi dan keunggulan produk terhadap minat beli sabun mandi lux.

Benowati, S. G., \& Purba, T. (2020). Journal Of Management, Accounting, Economic and Business. 01(02), 438-452.

Dimyati, M., Kartikasari, M. D., \& Sukarno, H. (2018). Pengaruh Green Marketing dan Pengetahuan Terhadap keputusan Pembelian dengan Mediasi minat Membeli konsumen Sariayu Martha Tilaar di Kota Jember. E-Journal Ekonomi Bisnis Dan Akuntansi, 5(2), 172. https://doi.org/10.19184/ejeba.v5i2.8680

Dr. Nugroho. J. Setiadi, S.E., M. . (2019). Perilaku Konsumen: Perspektif Kontemporer pada Motif, Tujuan, dan Keinginan Konsumen (Tujuh). PrenadaMedia Group.

Eliza, R., Sinaga, M., \& Kusumawati, A. (2018). PENGARUH YOUTUBE BEAUTY VLOGGER TERHADAP MINAT BELI KONSUMEN DAN DAMPAKNYA TERHADAP KEPUTUSAN PEMBELIAN PRODUK (Studi pada Pengguna Kosmetik Maybelline di Indonesia). Jurnal Administrasi Bisnis (JAB)/Vol, 63(1), 187196.

Imah, B. (2020). PENGARUH KESADARAN HALAL DAN LABEL HALAL TERHADAP KEPUTUSAN PEMBELIAN PRODUK KOSMETIK (Pada Konsumen Fakultas Ekonomi Dan Bisnis Islam Universitas Islam Negeri Sulthan Thaha Saifuddin Jambi) Skripsi. Journal of Chemical Information and Modeling, 53(9), 1689-1699.

Index, T. B. (2020). Top Brand Index.

Indonesia, kementrian P. R. (2013). Indonesia Lahan Subur Industri Kosmetik. Berita Industri.

Izzudin, A. (2018). Pengaruh Label Halal, Kesadaran Halal Dan Bahan Makanan Terhadap Minat Beli Makanan Kuliner. Penelitian Ipteks, 3(2), 100-114.

Kurniawan, R., \& Yuniarto, B. (2016). ANALISIS REGRESI: Dasar dan Penerapannya dengan R (pertama). KENCANA.

Kusnandar, V. B. (2019). Berapa Jumlah Penduduk Muslim Indonesia? Databoks.

Mustikasari, A. (2019). PENGARUH BRAND IMAGE TERHADAP MINAT BELI PADA PRODUK NATURE REPUBLIC ALOE VERA DI BANDUNG. 5(2), 652-659. 
Narita, T., \& Suyanto, A. (2019). Analisa Efektivitas Iklan Web Series Dengan Menggunakan Epic Model. Jurnal Mitra Manajemen, 3(1), 84-95.

Nathasi. (2017). Sariayu Martha Tilaar Perkuat Produk Kosmetik Halal. Gomuslim.Co.Id.

Permana, P. (2015). Analisis Pengaruh Efektivitas Iklan Dan Word Of Mouth Terhadap Brand Awareness, dan Nilai Pelanggan serta Dampaknya Terhadap Minat Beli Hand And Body Lotion Marina (Studi Kasus Pada Masyarakat di Kota Semarang).

Purba, T. A. (2019). Bisnis Kosmetik Indonesia Makin Moncer. Bisnis.Com.

Putri, A. (2018). Strength, Weakness, Opportunity,. 7(1), 2620-2631.

Rahmah, Ramdan, A. M., \& Danial, R. D. M. (2020). Sketsa bisnis "Pengaruh Religiusitas dan Produk Halal Terhadap Keputusan Memilih Kosmetik Pada Konsumen Muslim (Survei pada Civitas Akademika di Universitas Muhammadiyah Sukabumi). 7(1).

Ramdan, A. M., Rahayu, A., Wibowo, L. A., \& Dirgantari, P. D. (2021). The effect of uniqueness and student's experience in improving university image: Empirical study at private universities in Indonesia. Management Science Letters, 11(2), 357-364. https://doi.org/10.5267/j.msl.2020.9.034

Rangkuti, F. (2013). strategi promosi yang kreatif dan analisis kasus. PT Gramedia Pustaka Utama.

Septiani, F. (2018). Pengaruh Promosi Dan Produk Terhadap Minat Beli (JURNAL MAD). PT. Asuransi Jiwa Recapital.

Supriyatin, N. (2015). 1 Pengaruh Iklan Televisi Dan. 1-17.

Suryowati, B., \& Nurhasanah. (2020). ISSN:1978-8754 JURNAL MANAJEMEN DAN ORGANISASI VOLUME IX NOMOR 11, Juni 2020. IX(36).

Widyaningrum, P. W. (2019). Pengaruh Label Halal, Kesadaran Halal, Iklan, dan Celebrity Endorser terhadap Minat Pembelian kosmetik melalui variabel Persepsi sebagai Mediasi (Studi Pada Civitas Akademika Universitas Muhammadiyah Ponorogo). Capital: Jurnal Ekonomi Dan Manajemen, 2(2), 74. https://doi.org/10.25273/capital.v2i2.3984

Yuliyzar, I., \& Enjelita, S. D. (2020). Peningkatan Minat Beli Konsumen Melalui Daya Tarik Iklan Dan Label Halal Produk Lipcream Emina Pada Universitas Muhammadiyah Tangerang. Dynamic Management Journal, 4(1), 1-17. https://doi.org/10.31000/dmj.v4i1.2477

Yunus, N. S. N. M., Rashid, W. E. W., Ariffin, N. M., \& Rashid, N. M. (2014). Muslim's Purchase Intention towards Non-Muslim's Halal Packaged Food Manufacturer. Procedia - Social and Behavioral Sciences, 130, 145-154. https://doi.org/10.1016/j.sbspro.2014.04.018 